\title{
Can't beat the heat? Importance of cardiac control and coronary perfusion for heat tolerance in rainbow trout
}

\author{
Andreas Ekström ${ }^{1}\left[\right.$ ] Albin Gräns ${ }^{2} \cdot$ Erik Sandblom $^{1}$
}

Received: 4 July 2019 / Revised: 11 October 2019 / Accepted: 24 October 2019 / Published online: 9 November 2019

(c) The Author(s) 2019

\begin{abstract}
Coronary perfusion and cardiac autonomic regulation may benefit myocardial oxygen delivery and thermal performance of the teleost heart, and thus influence whole animal heat tolerance. Yet, no study has examined how coronary perfusion affects cardiac output during warming in vivo. Moreover, while $\beta$-adrenergic stimulation could protect cardiac contractility, and cholinergic decrease in heart rate may enhance myocardial oxygen diffusion at critically high temperatures, previous studies in rainbow trout (Oncorhynchus mykiss) using pharmacological antagonists to block cholinergic and $\beta$-adrenergic regulation showed contradictory results with regard to cardiac performance and heat tolerance. This could reflect intra-specific differences in the extent to which altered coronary perfusion buffered potential negative effects of the pharmacological blockade. Here, we first tested how cardiac performance and the critical thermal maximum $\left(\mathrm{CT}_{\max }\right)$ were affected following a coronary ligation. We then assessed how these performances were influenced by pharmacological cholinergic or $\beta$-adrenergic blockade, hypothesising that the effects of the pharmacological treatment would be more pronounced in coronary ligated trout compared to trout with intact coronaries. Coronary blockade reduced $\mathrm{CT}_{\max }$ by $1.5^{\circ} \mathrm{C}$, constrained stroke volume and cardiac output across temperatures, led to earlier cardiac failure and was associated with reduced blood oxygen-carrying capacity. Nonetheless, $\mathrm{CT}_{\max }$ and the temperatures for cardiac failure were not affected by autonomic blockade. Collectively, our data show that coronary perfusion improves heat tolerance and cardiac performance in trout, while evidence for beneficial effects of altered cardiac autonomic tone during warming remains inconclusive.
\end{abstract}

Keywords Autonomic nervous system $\cdot$ Adrenergic $\cdot$ Cardiac performance $\cdot$ Cholinergic $\cdot$ Critical thermal maximum

\section{Introduction}

In an era of climate change, mortalities caused by transient heat waves may be an increasingly important selection factor in aquatic organisms (Fey et al. 2015; Stillman 2019). Yet, the physiological mechanisms dictating thermal tolerance

Communicated by G. Heldmaier.

Electronic supplementary material The online version of this article (https://doi.org/10.1007/s00360-019-01243-7) contains supplementary material, which is available to authorized users.

Andreas Ekström

andreas.ekstrom@bioenv.gu.se

1 Department of Biological and Environmental Sciences, University of Gothenburg, PO Box 463, 40530 Göteborg, Sweden

2 Department of Animal Environment and Health, Swedish University of Agricultural Sciences, Göteborg, Sweden limits of ectothermic animals are not fully understood. Failure of both cardiorespiratory and neural functions has been suggested as underlying causes of heat death in ectotherms (MacMillan 2019; Ekström et al. 2016; Iftikar and Hickey 2013; Friedlander et al. 1976; Ern et al. 2015). While moderate acute warming typically elevates heart rate and cardiac output to meet oxygen demands, a plateau and subsequent reduction in heart rate and cardiac output is often observed at temperatures preceeding the critical thermal maximum $\left(\mathrm{CT}_{\max }\right)$. This suggests that the capacity of the cardiovascular system to deliver oxygen is compromised at critically high temperatures (Eliason and Anttila 2017; Sandblom et al. 2016; Ekström et al. 2014, 2016; Badr et al. 2016; Mendonca and Gamperl 2010; Ekström et al. 2017). An important factor limiting cardiac function during warming is the decline in the partial pressure of oxygen in venous blood $\left(P_{\mathrm{VO} 2}\right)$ during warming as tissue metabolic demand and oxygen extraction increase. This means that the partial pressure gradient driving oxygen diffusion from the cardiac lumen to 
the inner spongy myocardium declines at elevated temperatures (Ekström et al. 2016; Farrell and Clutterham 2003). This "luminal venous circulation" is the only route of myocardial oxygenation in most fish species, whereas the hearts of some species, such as salmonids, also receive oxygenated arterial blood via a coronary circulation that primarily perfuses the outer compact myocardium (Tota 1983; Farrell and Smith 2017; Ekström et al. 2017, 2018). The coronary circulation is believed to be of added importance during conditions of reduced environmental oxygen availability or elevated metabolic demands. For example, coronary flow in salmonids increases with moderate warming (Ekström et al. 2017), hypoxia (Axelsson and Farrell 1993; Gamperl et al. 1994, 1995) and exercise (Gamperl et al. 1995). Moreover, experimental coronary ligation in rainbow trout impaired ventral aortic blood pressure generation during both rest and swimming (Steffensen and Farrell 1998), and reduced the maximum metabolic rate (Ekström et al. 2018) and $\mathrm{CT}_{\max }$ (Ekström et al. 2017). However, whether such declines in whole animal performance following obstruction of coronary blood flow is related to impaired cardiac output generation in vivo has not been explored. Nonetheless, Kolok and Farrell (1994) demonstrated that coronary ligation impaired maximum stroke volume and cardiac output during exercise in Northern squawfish (Ptychocheilus oregonensis), but we are unaware of any study that has examined how coronary flow restrictions affect cardiac output during warming.

Negative effects of declining $P_{\mathrm{VO} 2}$ on cardiac performance with warming are probably mainly related to compromised cardiac contraction force, as hypoxia negatively affects the cardiac output, stroke volume and cardiac power output of in situ perfused heart preparations (Petersen and Gamperl 2010), and reduces the contractility of myocardial strip preparations in vitro (Overgaard and Gesser 2004; Roberts and Syme 2018; see also Driedzic and Gesser 1994). Yet, the plateau and reduction in heart rate at critically high temperatures observed in some fishes seems unrelated to oxygen availability. For example, we recently showed in European perch (Perca fluviatilis, no coronaries) that heart rate starts to plateau and decline at essentially similar high temperatures in normoxia and hyperoxia ( 200\% air saturation), whereas compensatory increases in stroke volume to maintain cardiac output as heart rate declined only occured when the $P_{\mathrm{VO} 2}$ was kept high in hyperoxia (Ekström et al. 2016). Even so, it remains largely unknown if the reduced heart rate at high temperatures is a sign of impending cardiac collapse or an active adaptive response, e.g., to protect viability and performance of the heart at critically high temperatures, and what role autonomic nervous control systems play in this regard.

While the autonomic nervous system plays a key role in governing cardiovascular performance of fish at benign temperatures, it may also be important during thermal and hypoxic stress (Sandblom and Axelsson 2011; Eliason and Anttila 2017). Cholinergic (i.e., vagal) inhibition of heart rate is a well-known adaptive response to hypoxia in fish (i.e., "hypoxic bradycardia"), and there are several reasons why it could also be important for improving myocardial function during heat stress. For example, as both heat stress and environmental hypoxia are conditions associated with reduced $P_{\mathrm{VO} 2}$ (Ekström et al. 2016; Clark et al. 2008b), a slowing of heart rate may be beneficial by increasing the time for luminal oxygen diffusion (Farrell 2007). A compensatory increase in stroke volume, increasing end-diastolic volume, would also serve to distend the myocardium and reduce oxygen diffusion distances (Farrell 2007). Additionally, as peak coronary blood flow occurs during diastole (Axelsson and Farrell 1993; Gamperl et al. 1994, 1995), a prolonged diastole likely enhances coronary oxygen delivery in species with a coronary circulation (Gamperl et al. 1994). Recent studies have also shown that myocardial electrical conductivity is impaired at extreme temperatures, causing ventricular depolarizations (i.e., QRS complexes) to become irregular and resulting in heart arrhythmia and reduced heart rate, while the spontaneous depolarization rate of the pacemaker tissue remains regular (Badr et al. 2016; Vornanen 2016). Therefore, a cholinergic slowing of the pacemaker rate may be important for the synchronization of ventricular excitation-contraction coupling, and to keep heart rate within functional limits under extreme warming (see Gilbert et al. 2019).

Adrenergic stimulation of the heart may also be important at thermal extremes, which is consistent with increased plasma catecholamine levels observed in various teleost species during heat stress (Currie et al. 2013; LeBlanc et al. 2012; Forster et al. 1998). Indeed, $\beta$-adrenergic stimulation improves in situ and in vitro cardiac function at elevated temperature (Gilbert et al. 2019; Aho and Vornanen 2001), as well as during hypoxemia, acidosis and hyperkalemia (Farrell et al. 1983; Hanson and Farrell 2007; Hanson et al. 2006; Kalinin and Gesser 2002; Roberts and Syme 2018), all of which are conditions associated with increased energy turnover at elevated temperature (Cech et al. 1976; Clark et al. 2008b; Heath and Hughes 1973).

To investigate the importance of cardiac autonomic regulation during heat stress, two recent studies on rainbow trout (Oncorhynchus mykiss) used atropine sulphate to block muscarinic receptors (leads to elevated routine heart rate) and sotalol hydrochloride to block $\beta$-adrenergic receptors (leads to reduced routine heart rate), and evaluated the effect of this pharmacological treatment on $\mathrm{CT}_{\max }$ and cardiorespiratory function during acute warming (Ekström et al. 2014; Gilbert et al. 2019). Despite very similar methodological approaches, the results from these studies were surprisingly contrasting. While we found no effect of pharmacological treatments on $\mathrm{CT}_{\max }$ or cardiac performance (Ekström et al. 
Table 1 Morphological characteristics, hematological variables and $\mathrm{Q}_{10}$ values for cardiovascular variables in sham operated and coronary ligated rainbow trout (Oncorhynchus mykiss)

\begin{tabular}{lcccc}
\hline & Sham operated & \multicolumn{2}{l}{ Coronary ligated } & \\
\cline { 3 - 5 } & Control & Control & Atropine & Sotalol \\
\hline Body mass $(\mathrm{g})$ & $654 \pm 29$ & $617 \pm 4^{\mathrm{a}}$ & $640 \pm 18^{\mathrm{a}}$ & $628 \pm 26^{\mathrm{a}}$ \\
Body length (mm) & $348 \pm 5$ & $345 \pm 4^{\mathrm{a}}$ & $345 \pm 3^{\mathrm{a}}$ & $343 \pm 3^{\mathrm{a}}$ \\
Condition factor & $1.5 \pm 0.03$ & $1.5 \pm 0.1^{\mathrm{a}}$ & $1.6 \pm 0.0^{\mathrm{a}}$ & $1.5 \pm 0.0^{\mathrm{a}}$ \\
Relative ventricle mass $(\mathrm{g})$ & $0.066 \pm 0.003$ & $0.076 \pm 0.007^{\mathrm{a}}$ & $0.065 \pm 0.003^{\mathrm{a}}$ & $0.066 \pm 0.002^{\mathrm{a}}$ \\
Compact myocardium $(\%)$ & $37.0 \pm 1.5$ & $32.5 \pm 1.4^{\mathrm{a}}$ & $32.6 \pm 2.1^{\mathrm{a}}$ & $30.5 \pm 1.9^{\mathrm{a}}$ \\
Hematocrit $(\%)$ & $41.8 \pm 1.5^{*}$ & $31.7 \pm 1.7^{\mathrm{a}}$ & $30.6 \pm 1.8^{\mathrm{a}}$ & $29.2 \pm 2.3^{\mathrm{a}}$ \\
Hemoglobin $\left(\mathrm{g} \mathrm{l^{-1 }}\right)$ & $94.2 \pm 2.2^{*}$ & $72.2 \pm 4.1^{\mathrm{a}}$ & $73.5 \pm 2.4^{\mathrm{a}}$ & $74.3 \pm 5.6^{\mathrm{a}}$ \\
Mean corpuscular hemoglobin & $226.9 \pm 4.3$ & $227.5 \pm 1.9^{\mathrm{a}}$ & $243.5 \pm 9.7^{\mathrm{ab}}$ & $255.7 \pm 5.0^{\mathrm{b}}$ \\
$\quad$ concentration $\left(\mathrm{g} 1^{-1}\right)$ & & & & \\
$\mathrm{Q}_{10}$ for cardiac output $\left(10{ }^{\circ} \mathrm{C}-\mathrm{PT}\right)$ & $2.4 \pm 0.2$ & $2.0 \pm 0.3$ & $1.5 \pm 0.1$ & $2.0 \pm 0.2$ \\
$\mathrm{Q}_{10}$ for heart rate $\left(10^{\circ} \mathrm{C}-\mathrm{PT}\right)$ & $1.7 \pm 0.05$ & $1.7 \pm 0.06$ & $1.6 \pm 0.04$ & $2.1 \pm 0.1$ \\
\hline
\end{tabular}

Sham-operated and coronary-ligated control groups were injected with saline $\left(0.9 \% \mathrm{NaCl}, 1 \mathrm{ml} \mathrm{kg}{ }^{-1}\right)$. Atropine and Sotalol treated coronary ligated trout were injected with saline containing atropine sulphate $\left(1.2 \mathrm{mg} \mathrm{kg}^{-1}\right)$ and sotalol hydrochloride $\left(2.7 \mathrm{mg} \mathrm{kg}^{-1}\right)$, respectively. Asterisks $\left(^{*}\right)$ denote statistical differences $(P \leq 0.05)$ between sham-operated and coronary-ligated control groups. Dissimilar letters in coronary-ligated trout depicts statistical differences $(P \leq 0.05)$ among pharmacological treatment groups. Values are mean \pm SEM
2014), Gilbert et al. (2019) reported significant reductions in $\mathrm{CT}_{\max }$ and cardiac performance during warming when atropine and sotalol were administered both separately and in combination. These contrasting results may be attributed to body mass-dependent differences in the reliance on coronary myocardial perfusion (mean body masses: $357 \mathrm{~g}$ in Gilbert et al. (2019) and $683 \mathrm{~g}$ in Ekström et al. (2014)), as the relative proportion of compact myocardium increases with body mass in salmonids (Brijs et al. 2016; Farrell et al. 2012). Consequently, in our study on larger trout, increases in coronary flow may have buffered potential negative effects of the pharmacological blockade. From this, it could be hypothesised that changes in cardiac autonomic and hormonal tone are more important determinants of thermal tolerance in smaller fish with a lower dependence on coronary perfusion of the heart, as well as in situations where coronary flow is restricted such as in salmonids with coronary arteriosclerosis (i.e., vascular plaque formation). Such pathological conditions are known to develop at fast growth rates in aquaculture and in response to environmentally stressful conditions (e.g., environmental warming) that elevates cardiac workload, but the functional significance of this is poorly understood (see Farrell 2002).

To test the ideas outlined above, the current study had two main objectives. First, using previously established experimental protocols (Ekström et al. 2014, 2017), we examined how surgical ligation of the coronary artery affected cardiac output during acute warming until $\mathrm{CT}_{\max }$ in rainbow trout instrumented with ventral aortic flow probes. We hypothesised that trout with obstructed coronaries would exhibit reduced capacity to maintain cardiac output and stroke volume during warming, which would be associated with an earlier onset of cardiac failure at high temperatures and explain the reduced $\mathrm{CT}_{\max }$ previously observed in coronary ligated trout (Ekström et al. 2017). Second, to test the hypothesis that autonomic regulation of the heart may be important for cardiovascular performance and thermal tolerance in fish with limited or no coronary perfusion, we subjected coronary-ligated trout to acute warming following pre-treatment with atropine, sotalol or saline as a control.

\section{Materials and methods}

\section{Experimental animals and holding conditions}

Adult rainbow trout (Oncorhynchus mykiss, Walbaum 1792, see Table 1 for morphometric data) of mixed sexes were obtained from a commercial fish farm (Vänneåns fiskodling AB, Knäred, Sweden). The fish were kept in holding tanks supplied with a continuous flow of freshwater at $10^{\circ} \mathrm{C}$ and a 12:12 h light:dark photoperiod for at least 4 weeks prior to the experiments. Fish were fed with commercial pellets three times per week, but feeding was withheld 1 week prior to experimentation.

\section{Anaesthesia and surgery}

Fish were anaesthetized in $10{ }^{\circ} \mathrm{C}$ freshwater containing MS-222 (Tricaine methane-sulfonate; $150 \mathrm{mg} \mathrm{kg}^{-1}$ ) buffered with $\mathrm{NaHCO}_{3}\left(300 \mathrm{mg} \mathrm{kg}^{-1}\right)$. Body mass and length were determined and the fish were placed ventral side up on wet foam on a surgery table. Surgical anaesthesia was maintained by continuously irrigating the gills with $10{ }^{\circ} \mathrm{C}$ 
freshwater containing MS-222 $\left(75 \mathrm{mg} \mathrm{kg}^{-1}\right)$ and $\mathrm{NaHCO}_{3}$ $\left(150 \mathrm{mg} \mathrm{kg}^{-1}\right)$.

To record cardiovascular variables (i.e., heart rate and relative changes in cardiac output and stroke volume), a silicone cuff with a $20 \mathrm{MHz}$ Doppler crystal (Model ES, 1.6-1.8 mm; Iowa Doppler products, Iowa City, IA, USA) was used. A small incision was made in the isthmus to expose the ventral aorta and the flow probe was placed around the vessel and secured by a 4-0 silk suture. The wire from the probe was sutured to the skin along the opercular cavity and anterior to the dorsal fin. For drug administration, the body wall was punctured $\sim 2-4 \mathrm{~cm}$ posterior to the pectoral fin using an injection needle (14G $\times 3-1 / 4 ")$, and a PE-50 catheter was inserted into the abdominal cavity and secured to the skin using 4-0 silk sutures.

The experiments included two different surgical treatments. In the first treatment, referred to as "coronary ligated", the coronary artery was exposed by blunt dissection via the incision made in the isthmus (see above) and ligated with 6-0 silk suture to permanently obstruct coronary blood flow. In the second treatment, referred to as "sham operated", fish underwent the same surgical procedure except that the coronary artery was not ligated, which meant that coronary blood flow remained unrestricted. Following the surgical procedures, all fish were allowed to recover for at least $24 \mathrm{~h}$ before starting the experimental protocol. The fish were placed either directly in the experimental chambers (width: $130 \mathrm{~mm}$; length: $340 \mathrm{~mm}$; height: $170 \mathrm{~mm}$ ), or in opaque holding tubes (length: $750 \mathrm{~mm}$, diameter: $150 \mathrm{~mm}$ ) placed in separate holding tanks supplied with fully oxygenated water at $10{ }^{\circ} \mathrm{C}$. Fish recovered in holding tubes were transferred to the experimental setup at least $16 \mathrm{~h}$ prior to experimentation.

\section{Experimental protocols and tissue sampling}

Resting cardiovascular variables at $10{ }^{\circ} \mathrm{C}$ were first recorded in all fish for at least $1-2 \mathrm{~h}$, or until stable resting values had been attained. After this, the coronary-ligated fish were divided into three pharmacological treatment groups $(n=8)$ and injected with either atropine sulphate $\left(1.2 \mathrm{mg} \mathrm{kg}^{-1}\right)$ to block muscarinic receptors, sotalol hydrochloride $\left(2.7 \mathrm{mg} \mathrm{kg}^{-1}\right)$ to block $\beta$-adrenergic receptors or saline $(0.9 \% \mathrm{NaCl})$ as untreated control (see Ekström et al. 2014). The sham-operated fish were injected with the saline control treatment to allow comparison with the coronary-ligated control group. All injections were administered as $1 \mathrm{ml} \mathrm{kg}^{-1}$ boluses followed by $0.5 \mathrm{ml}$ of saline to flush the catheter. All pharmacological substances and chemicals were purchased from Sigma-Aldrich (St Louis, MO, USA).

When stable post-injection values had been attained (typically within 30-90 $\mathrm{min}$ ), the temperature was raised by $5{ }^{\circ} \mathrm{C} \mathrm{h}^{-1}$ until reaching $20^{\circ} \mathrm{C}$ (i.e., $\sim 30 \mathrm{~min}$ of temperature increase followed by $\sim 30 \mathrm{~min}$ at steady state for each $5{ }^{\circ} \mathrm{C}$ step). Thereafter, the temperature was raised in smaller steps of $3{ }^{\circ} \mathrm{C} \mathrm{h}^{-1}$ (i.e., $\sim 15 \mathrm{~min}$ for the temperature increase followed by $\sim 5$ min at steady state for each $1{ }^{\circ} \mathrm{C}$ step) until the temperature was reached where the fish lost the righting response, which was defined as the critical thermal maximum (i.e., $\mathrm{CT}_{\max }$ ) (see Beitinger et al. 2000). Cardiovascular variables were recorded continuously during the thermal challenge, and when reaching $\mathrm{CT}_{\max }$, the fish were immediately removed from the experimental chambers and euthanized with a sharp blow to the head. A blood sample was quickly withdrawn from the caudal vessels using a heparinized syringe. Blood hemoglobin concentration was determined immediately using a hand-held $\mathrm{Hb} 201^{+}$meter (Hemocue AB, Ängelholm, Sweden), and the values were calibrated for fish blood according to Clark et al. (2008a). Hematocrit was determined using heparinized microhematocrit tubes, spun at $10,000 \mathrm{~g}$ for $5 \mathrm{~min}$. The heart ventricle was dissected free, blotted dry and weighed. The heart was then placed in $70 \%$ ethanol for at least $48 \mathrm{~h}$, after which the ventricle was cut in half and the spongy and compact myocardial layers were carefully peeled apart under a dissecting microscope using the protocol described by Farrell et al. (2007). The heart tissues were dried in an oven at $60^{\circ} \mathrm{C}$ for $24 \mathrm{~h}$ before the dry weights were determined for subsequent calculation of the proportion of compact myocardium (see details below).

\section{Data acquisition and calculations}

The Doppler probe was connected to a directional-pulsed Doppler flowmeter (545C-4, Bioengineering, University of Iowa, Iowa City, USA) and the signal range was adjusted to obtain the maximum signal intensity before each experimental protocol. The water temperature in the experimental setup was controlled and recorded continuously using a custombuilt thermostat and temperature logger (EW 7221, Crn Tecnopart, Barcelona, Spain) connected to a $9 \mathrm{~kW}$ water heater (K060, Värmebaronen, Kristianstad, Sweden) in an adjacent water container. The analog outputs from the recording equipment were relayed to a PowerLab system (AD Instruments, Sydney, Australia), connected to a computer running Labchart Pro software (v7.2.2, AD Instruments, Castle Hill, Australia). Heart rate was determined from the pulsating blood flow traces using the cyclic measurements module in LabChart Pro. Cardiac output was determined from the changes in blood flow velocity and stroke volume was calculated as the quotient of cardiac output divided by heart rate. Relative changes in cardiac output and stroke volume were determined from the changes in blood flow velocity with the resting value before drug or saline injection defined as $100 \%$. Mean values for all cardiac variables were taken from the last $3 \mathrm{~min}$ before drug injection or temperature increments 
when variables were stable and had reached a steady state. The temperatures where peak heart rate $\left(\mathrm{TP}_{\mathrm{HR}}\right)$ and peak cardiac output $\left(\mathrm{TP}_{\mathrm{CO}}\right)$ were reached were determined for individual fish. These temperatures were defined as the respective highest temperatures reached before heart rate and cardiac output started to progressively decline. Mean values for cardiac output, heart rate and stroke volume at both $\mathrm{TP}_{\mathrm{HR}}$ and $\mathrm{TP}_{\mathrm{CO}}$ were calculated for each treatment group. Thermal coefficient values, i.e., $\mathrm{Q}_{10}$ 's, were calculated between the initial temperature (i.e., $10{ }^{\circ} \mathrm{C}$ ) and the TP's for heart rate and cardiac output according to the following equation:

$\mathrm{Q}_{10}=\left(R_{y} / R_{10}\right)^{10 /\left(T_{y}-T_{10}\right)}$,

where $R_{10}$ is the initial heart rate or cardiac output at $10^{\circ} \mathrm{C}$ and $R_{y}$ is the heart rate or cardiac output at the peak temperature. $T_{10}$ is $10{ }^{\circ} \mathrm{C}$ and $T_{y}$ is the TP for each variable. To estimate relative changes in cholinergic and adrenergic tones on the heart during warming, the numerical differences in heart rate (i.e., $\Delta$ heart rate) were calculated between the control group and the atropine- and sotalol-treated groups, respectively (see Ekström et al. 2014). The percentage of compact ventricular myocardium was calculated using the following equation:

$M_{\text {compact }} / M_{\text {ventricle }} \times 100$,

where $M_{\text {compact }}$ and $M_{\text {ventricle }}$ represent the dry masses of the compact myocardial tissue and the entire ventricle (i.e., combined spongy and compact myocardium), respectively.

Condition factor was calculated according to the following equation:

Condition factor $=(100 \times$ Body mass $) /$ standard length $^{3}$, with body mass in grams and the standard length in centimetres. Mean corpuscular hemoglobin concentration (MCHC) was determined using the following equation:

$\mathrm{MCHC}=$ Hemoglobin concentration/(Hematocrit/100).

\section{Statistics}

All values are presented as mean \pm SEM unless otherwise stated. For all tests, statistical significance was accepted at $P \leq 0.05$. Normality (mean values and residuals) and homogeneity of variance were determined using Shapiro-Wilk's and Levene's tests, respectively. When the assumption of normality was not met, the data were log-transformed (relative ventricle mass, MCHC, stroke volume and cardiac output at $\left.\mathrm{TP}_{\mathrm{HR}}\right)$. An independent-sample $t$ test was used to analyse differences between sham-operated and coronaryligated trout with regard to morphological characteristics, blood parameters, cardiac variables and $\mathrm{CT}_{\max }$. One-way ANOVAs were used to compare pre-treatment cardiovascular variables within treatment groups at $10{ }^{\circ} \mathrm{C}$, as well as differences between pharmacological treatment groups in regards to morphological characteristics, cardiac performance variables and $\mathrm{CT}_{\max }$. Significant main effects were further explored with a Bonferroni post hoc test for pairwise comparisons among treatment groups, thus adjusting the $P$ values for multiple testing. Paired $t$ tests were performed to assess the effects of the pharmacological treatments on heart rate at $10{ }^{\circ} \mathrm{C}$ (i.e., pre- vs. post-injection). Similarly, one-sample $t$ tests were used to analyse whether post-injection values for the relative variables (i.e., cardiac output and stroke volume) differed from the initial $100 \%$ value. A linear mixed model was used to evaluate the effects of temperature and pharmacological treatments on cardiac performance traits during acute warming. In the mixed model, individuals were set as subjects and temperature as the independent repeated measures factor. Temperature, treatment and its interaction (i.e., temperature $\times$ treatment) were included as fixed factors in the model. A first-order autoregressive covariance structure was used as this provided the best fit to the data (i.e., the lowest Akaike's Information Criterion). For heart rate and cardiac output, only values leading up to the lowest TP across treatment groups $\left(21{ }^{\circ} \mathrm{C}\right.$ for both cardiac, heart rate and stroke volume) were included in the model. As the coronary ligated control group was used twice in the analyses, Bonferroni correction (multiplying the $P$ values by 2) was used to compensate for multiple comparisons with this group. Pearson's correlation coefficients $\left(P_{\text {corr }}\right)$ were calculated to evaluate potential correlations between $\mathrm{CT}_{\max }$ and morphometrical, hematological, and cardiovascular variables.

\section{Results}

\section{Effects of coronary ligation on temperature tolerance and cardiac performance during warming in rainbow trout}

There were no differences in morphometrical traits between coronary-ligated and sham-operated trout (Table 1). However, there was a trend for a lower proportion of compact myocardium in the coronary-ligated fish $(P=0.1$; Table 1$)$.

At $10{ }^{\circ} \mathrm{C}$, coronary-ligated fish had a significantly higher resting heart rate $\left(62.8 \pm 2.1\right.$ beats $\left.\mathrm{min}^{-1}\right)$ compared to shamoperated fish $\left(50.8 \pm 1.8\right.$ beats $\mathrm{min}^{-1} ; T_{15}=4.4 ; P=0.001$; Fig. 1b). Cardiac output and heart rate increased significantly with warming in both groups $\left(10-21^{\circ} \mathrm{C}, F_{3,23}=21.9\right.$; $P<0.001$ and $F_{3,77}=173.5 ; P<0.001$, respectively; Fig. 1a, b), and there were no differences in the thermal sensitivity $\left(\mathrm{Q}_{10}\right)$ of cardiac output or heart rate (Table 1). Even so, between 10 and $21{ }^{\circ} \mathrm{C}$, the coronary-ligated fish exhibited significantly elevated heart rate $\left(F_{3,31}=9.3 ; P<0.000\right.$; Fig. 1b), combined with a clear trend towards lowered 
Fig. 1 The effects of coronary ligation on cardiovascular variables during acute warming in rainbow trout, Oncorhynchus mykiss. The variables are relative cardiac output (a), heart rate (b) and relative stroke volume (c) in coronary-ligated (white circles, $n=8$ ) and shamoperated trout (black squares, $n=7$ ). The arrows denote the respective temperatures at which cardiac output or heart rate peaked $\left(\mathrm{TP}_{\mathrm{CO}}\right.$ and $\mathrm{TP}_{\mathrm{HR}}$, respectively), where after these variables started to decline. Asterisks (*) denote significant differences between coronaryligated and sham-operated fish. The inset table shows the statistical details from the mixed model analysis evaluating the effects of surgical obstruction of the coronary artery and warming between 10 and $21^{\circ} \mathrm{C}$, the latter temperature being the lowest individual $\mathrm{TP}_{\mathrm{CO}}$ or $\mathrm{TP}_{\mathrm{HR}}$ across groups (indicated by the shaded area). Statistical significance was accepted at $P \leq 0.05$. Values are mean \pm SEM

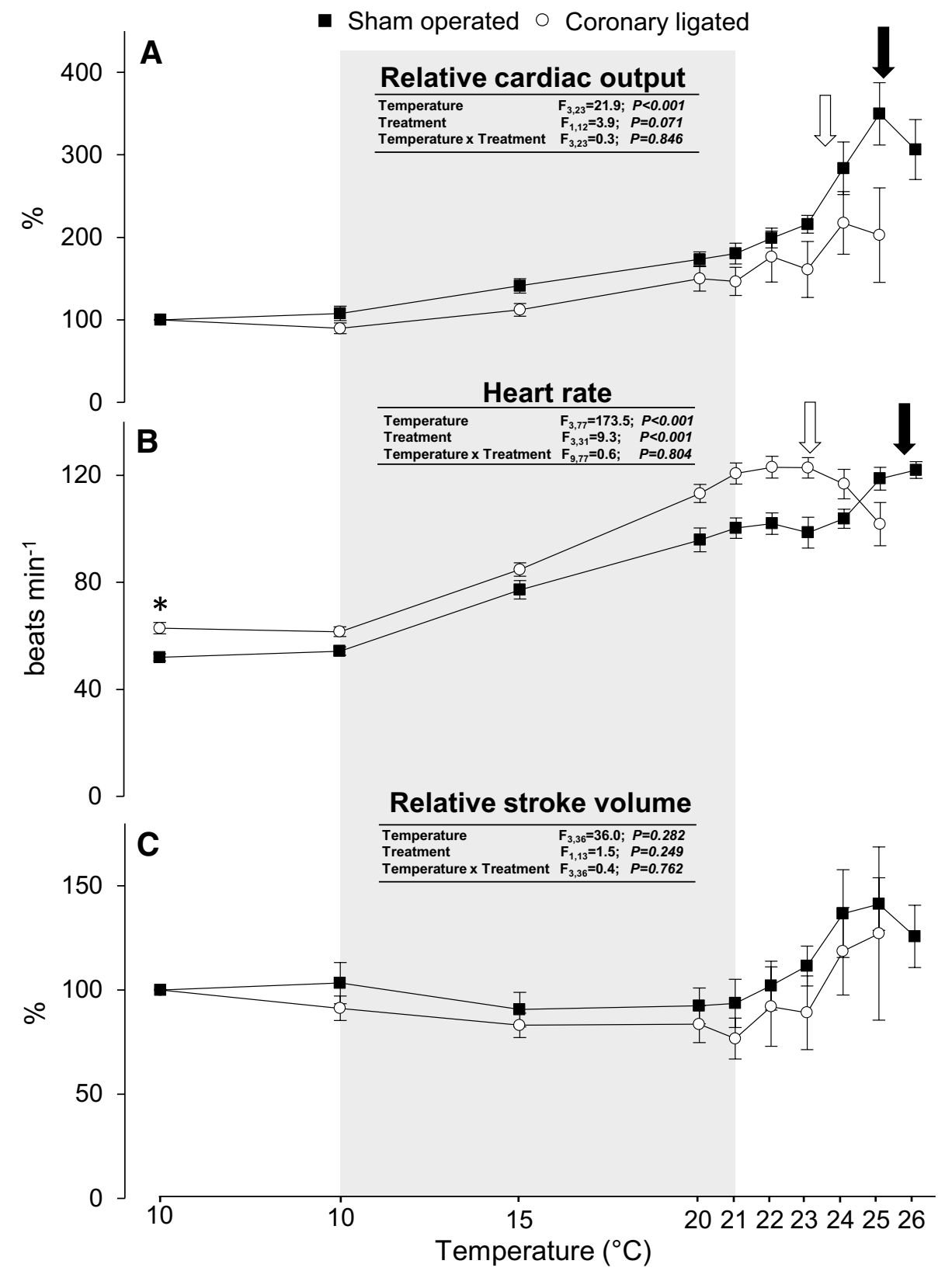

cardiac output compared to sham-operated fish $(P=0.071$; Fig. 1a). Even so, stroke volume was not significantly affected by temperature between 10 and $21^{\circ} \mathrm{C}$, and there were no statistical differences in relative stroke volume between groups during warming (Fig. 1c).

Coronary ligation resulted in significantly reduced $\mathrm{CT}_{\text {max }}$ compared to sham-operated fish $\left(25.4\right.$ vs. $26.9{ }^{\circ} \mathrm{C}$; $F_{15}=-3.5 ; P=0.006$; Fig. 2a). Moreover, the temperatures for peak cardiac output and peak heart rate were consistently lower in coronary-ligated compared to sham-operated trout (23.6 vs. $25.1{ }^{\circ} \mathrm{C} ; T_{13}=-2,6 ; P=0.044$, and 23.1 vs. $25.9^{\circ} \mathrm{C} ; T_{14}=-4.4 ; P=0.001$, respectively; Fig. $\left.2 \mathrm{~b}, \mathrm{c}\right)$. Both groups displayed similar heart rates at their respective
$\mathrm{TP}_{\mathrm{CO}}\left(\sim 120\right.$ beats $\mathrm{min}^{-1}$; Fig. $\left.2 \mathrm{e}\right)$, but cardiac output was significantly lower in ligated trout at $\mathrm{TP}_{\mathrm{CO}}(190$ vs. $380 \%$; $T_{12}=-4.3 ; P=0.002$; Fig. 2 d), which coincided with a clear trend for a lower stroke volume (102 vs. $163 \% ; P=0.09$; Fig. 2f). Similarly, even though heart rate was comparable between groups at their respective $\mathrm{TP}_{\mathrm{HR}}\left(\sim 128\right.$ beats $\min ^{-1}$; Fig. 2h), both cardiac output and stroke volume were significantly lower in ligated trout compared to the sham-operated controls at the $\mathrm{TP}_{\mathrm{HR}}\left(177\right.$ vs. $330 \% ; T_{13}=-2.9 ; P=0.03$ and 87 vs. $133 \% ; T_{13}=-3.7 ; P=0.005$, respectively, Fig. $2 \mathrm{~g}$, i). Consistent with these findings, there was a positive correlation between $\mathrm{CT}_{\max }$ and $\mathrm{TP}_{\mathrm{HR}}$ in both coronary-ligated and sham-operated control fish $\left(P_{\text {corr }}=0.713 ; P=0.047\right.$ and 


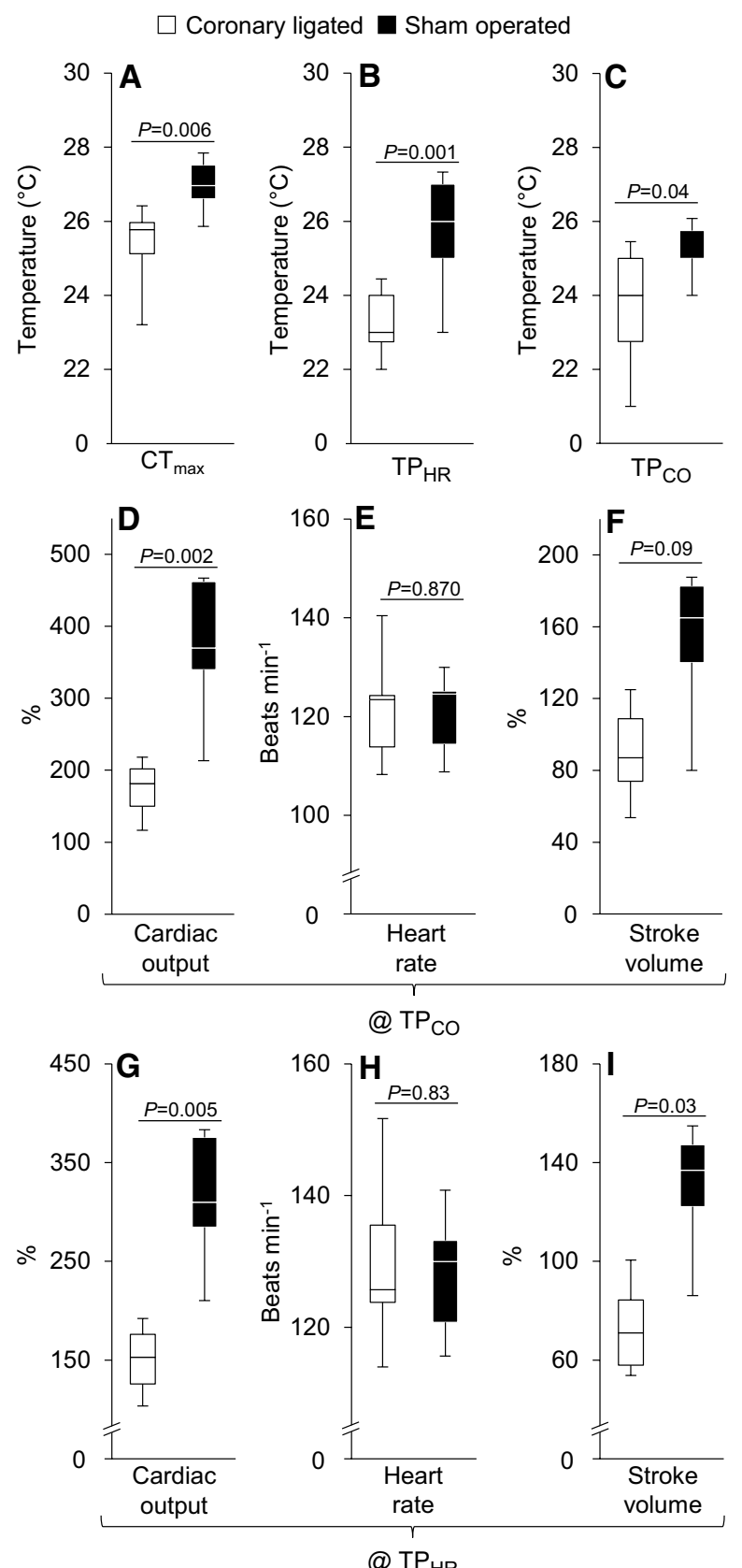

$@ \mathrm{TP}_{\mathrm{HR}}$

Fig. 2 Thermal limits of cardiovascular variables in coronary-ligated and sham-operated rainbow trout, Oncorhynchus mykiss. a The critical thermal maximum $\left(\mathrm{CT}_{\max }\right)$ and $\mathbf{b}$, $\mathbf{c}$ temperatures for peak heart rate and cardiac output $\left(\mathrm{TP}_{\mathrm{HR}}\right.$ and $\mathrm{TP}_{\mathrm{CO}}$, respectively) in coronaryligated (white bars, $n=7$ ) and sham-operated trout (black bars, $n=7$ ). Panels d-f display heart rate, cardiac output and stroke volume at $\mathrm{PT}_{\mathrm{CO}}$, and panels $\mathbf{g}-\mathbf{i}$ display the same variables at the $\mathrm{PT}_{\mathrm{HR}}$. The $P$ values show statistical differences between treatment groups. Statistical significance was accepted at $P \leq 0.05$

$P_{\text {corr }}=0.831 ; P=0.020 ;$ Fig. 3 a). There was also a positive correlation between $\mathrm{CT}_{\max }$ and $\mathrm{TP}_{\mathrm{CO}}$ for the sham-operated control fish $\left(P_{\text {corr }}=0.689 ; P=0.04\right)$, with a similar trend
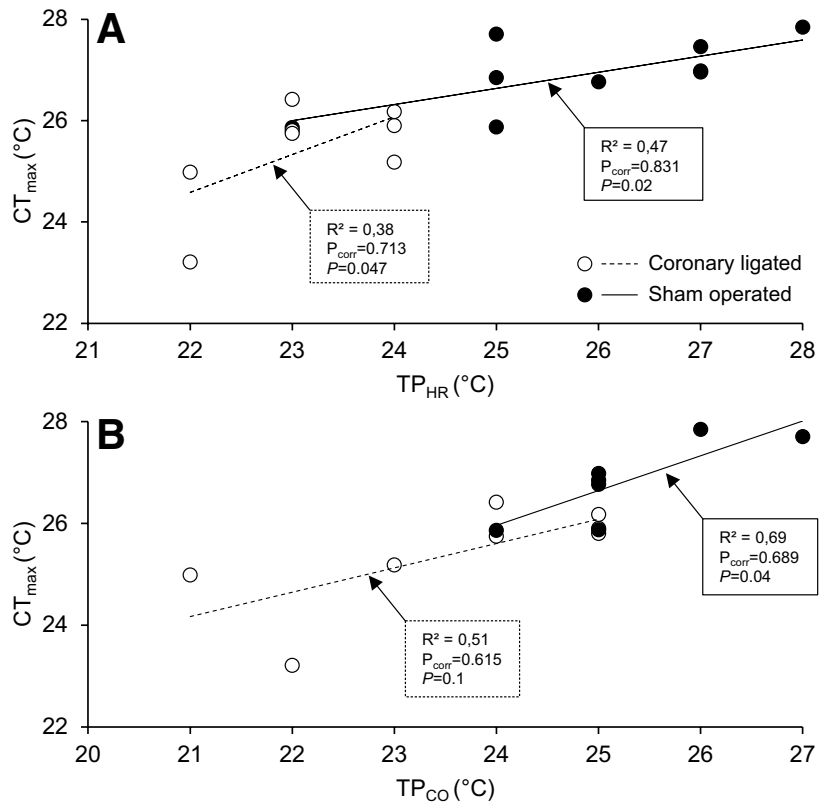

Fig. 3 Correlations between cardiovascular and whole animal thermal tolerance limits in coronary-ligated and sham-operated rainbow trout (Oncorhynchus mykiss). Linear regressions between the critical thermal maximum $\left(\mathrm{CT}_{\max }\right)$ and the temperatures for peak heart rate $\left(\mathrm{TP}_{\mathrm{HR}}, \mathbf{a}\right)$ and peak cardiac output $\left(\mathrm{TP}_{\mathrm{CO}}, \mathbf{b}\right)$ in coronary ligated (white circles, dashed trend lines) and sham operated trout (black circles, solid trend lines). The Pearson correlation coefficient $\left(P_{\text {corr }}\right)$ shows the strength of the linear relationship between the two variables. The $P$ values show whether correlations within treatment groups are statistically significant $(P \leq 0.05)$. Values are mean \pm SEM

observed in the coronary-ligated trout $\left(P_{\text {corr }}=0.615 ; P=0.1\right.$; Fig. 3b).

The hematocrit and hemoglobin concentration, which were analysed at the end of the warming protocol, were significantly lower in coronary ligated fish $\left(T_{16}=-4.4\right.$; $P=0.002$ and $T_{16}=-5.0 ; P<0.001$, respectively), whereas MCHC was similar (Table 1). In coronary-ligated fish, positive correlations were found between hematocrit and $\mathrm{TP}_{\mathrm{CO}}$ and $\mathrm{TP}_{\mathrm{HR}}\left(P_{\text {corr }}=0.894 ; P=0.003\right.$ and $P_{\text {corr }}=0.725$; $P=0.04$, respectively, Fig. $4 \mathrm{a}$ ), as well as between hemoglobin concentration and $\mathrm{TP}_{\mathrm{CO}}$ and $\mathrm{TP}_{\mathrm{HR}}\left(P_{\text {corr }}=0.704\right.$; $P=0.051$ and $P_{\text {corr }}=0.862 ; P=0.006$, respectively, Fig. 4b). No such relationships were detected in the sham-operated fish.

\section{Effects of autonomic blockade on temperature tolerance and cardiac performance during warming in coronary-ligated rainbow trout}

There were no differences in morphometrical traits among pharmacological treatment groups (Table 1), and prior to the pharmacological treatments, there were no differences in routine heart rate among groups, which averaged $62 \pm 1$ 


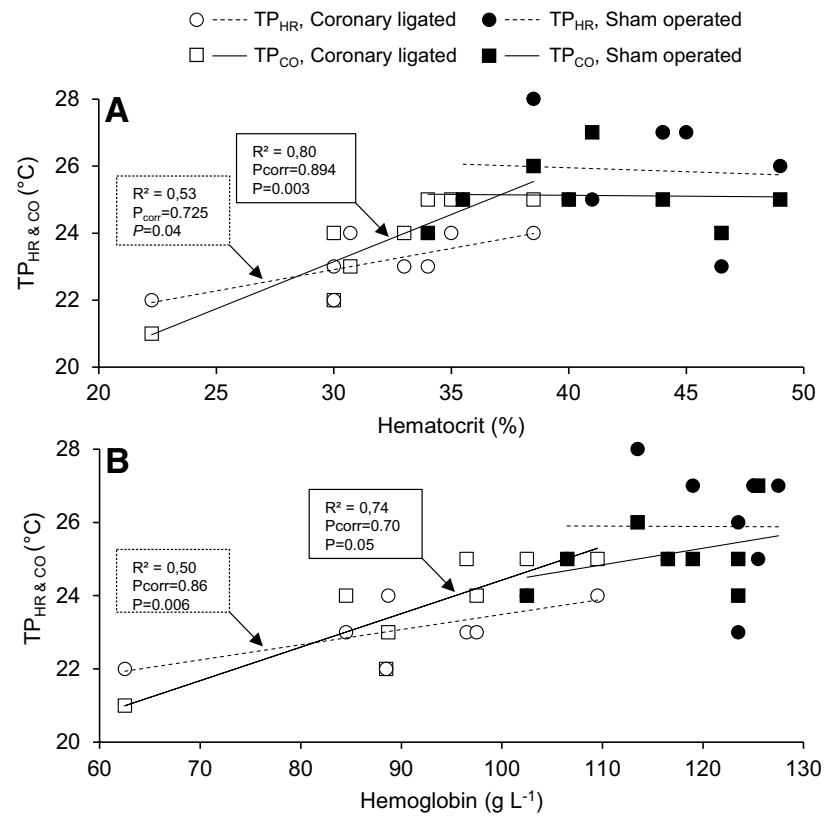

Fig. 4 Correlations between cardiovascular performance and blood oxygen-carrying capacity in coronary-ligated and sham-operated rainbow trout (Oncorhynchus mykiss). Linear regressions between the temperatures for peak heart rate $\left(\mathrm{TP}_{\mathrm{HR}}\right.$, circles, dashed trend lines) and cardiac output $\left(\mathrm{TP}_{\mathrm{CO}}\right.$, squares, solid trend lines), and hematocrit (a) and hemoglobin (b) in coronary ligated (white symbols) and sham operated trout (black symbols). The Pearson correlation coefficient $\left(P_{\text {corr }}\right)$ signifies the strength of the linear relationship between the variables. The $P$ values show whether the correlations were statistically significant within treatment groups $(P \leq 0.05)$. Details are only depicted for statistically significant correlations (i.e., in coronary ligated trout). Values are mean \pm SEM

beats $\min ^{-1}$ (Fig. 5 b). At $10{ }^{\circ} \mathrm{C}$, the atropine treatment induced a $9 \%$ elevation in heart rate $\left(59-65\right.$ beats $\mathrm{min}^{-1}$; $\left.T_{7}=-3.046 ; P=0.019\right)$, whereas the sotalol treatment reduced heart rate by $34 \%$ in coronary-ligated trout (64-42 beats $\min ^{-1}, T_{7}=10.385 ; P<0.001$, Fig. $5 b$ ). The changes in heart rate with atropine and sotalol resulted in corresponding increases $(18 \%)$ and decreases $(33 \%)$ in routine cardiac output $\left(T_{7}=3.0 ; P=0.019\right.$ and $T_{7}=-4.3 ; P=0.003$, respectively; Fig. 5a), while stroke volume was unchanged (Fig. 5c).

Cardiac output and heart rate increased significantly between 10 and $21{ }^{\circ} \mathrm{C}\left(F_{3,30}=19.0 ; P<0.001\right.$ and $F_{3,34}=196.0 ; P<0.001$, respectively), whereas stroke volume decreased with warming $\left(F_{3,57}=6.7 ; P=0.001\right)$ across pharmacological treatment groups (Fig. $5 \mathrm{a}-\mathrm{c}$ ). Nonetheless, sotalol-treated trout displayed a significantly reduced cardiac output compared to control and atropine-treated fish $\left(F_{2,22}=9.9 ; P=0.001\right)$, which was explained by a significantly lower heart rate compared to both control and atropine-treated fish $\left(F_{2,22}=12.0 ; P<0.001 ;\right.$ Fig. 5a, b). There were no significant interactions between pharmacological treatment and temperature indicating that there were no differences in the thermal sensitivity among treatment groups. The numerical difference in heart rate ( $\Delta$ heart rate) between control and atropine-treated fish did not exceed 8 beats $\min ^{-1}$ during the warming protocol until $\mathrm{TP}_{\mathrm{HR}}$ was reached, whereas the $\Delta$ heart rate between control and sotalol-treated trout ranged between 17 and 21 beats min $^{-1}$ during warming. There were no differences among treatment groups in $\mathrm{CT}_{\max }\left(\sim 25.2^{\circ} \mathrm{C}\right), \mathrm{TP}_{\mathrm{HR}}$ or $\mathrm{TP}_{\mathrm{CO}}(\sim 23.2$ and $23.5^{\circ} \mathrm{C}$, respectively; Fig. $6 \mathrm{a}-\mathrm{c}$ ). Moreover, cardiac output, heart rate and stroke volume were not significantly different at their respective peak temperatures (Fig. 6d-i). Similarly, the hematological traits at the end of the warming protocol did not differ among the three pharmacological treatment groups, with the only exception that sotalol-treated fish had a significantly higher MCHC $\left(F_{2,13}=14.9 ; P<0.001\right.$, Table 1).

\section{Discussion}

\section{Effects of blocked coronary perfusion on routine cardiac performance and autonomic control}

Chronic blocking of coronary perfusion resulted in elevated heart rate. This was likely mediated by a release of vagal inhibitory tone, as treatment with the muscarinic receptor antagonist atropine had very little effect on heart rate in coronary-ligated trout. This finding is consistent with previous studies on coronary-ligated rainbow trout (Steffensen and Farrell 1998; Ekström et al. 2017, 2018). The elevated heart rate did seemingly not involve an altered adrenergic tone on the cardiac pacemaker, as the reduction in heart rate with the $\beta$-adrenergic receptor antagonists sotalol was very similar to previously reported responses to this drug in trout with unrestricted coronary blood flow (reductions by 33 vs. $34 \%$, (Ekström et al. 2014)). The elevated routine heart rate presumably reflected a compensatory response to maintain cardiac output as stroke volume was likely compromised after the coronary blockade (see below). However, a limitation of the present study is that only relative changes in cardiac output and stroke volume were assessed, and thus, it is currently unknown to what extent routine cardiac output and stroke volume in absolute terms are affected by the coronary ligation procedure. Future experiments should evaluate the impact of coronary perfusion on absolute cardiac output.

Interestingly, coronary-ligated trout displayed a trend towards a reduced proportion of compact myocardium, which was reduced by $\sim 12 \%$ relative to the sham-operated trout (32.5\% vs. $37.0 \%$ compact myocardium) when examined $\sim 1.5$ days after surgery. This is similar to previous observations in chronically (28-52 days) coronary-ligated trout (Farrell et al. 1990), and suggests that the loss of 
Fig. 5 The effects of autonomic blockade on cardiovascular variables in coronary-ligated rainbow trout (Oncorhynchus mykiss) during acute warming. The variables are relative cardiac output (a) heart rate (b) and relative stroke volume (c) in coronary-ligated trout treated (at dashed line) with $0.9 \%$ $\mathrm{NaCl}$ (control, white circles, $n=8)$, atropine (1.2 $\mathrm{mg} \mathrm{kg}^{-1}$, black circles, $n=8$ ) or sotalol $\left(2.7 \mathrm{mg} \mathrm{kg}^{-1}\right.$, grey circles, $n=8$ ). Differently colored arrows denote the temperatures for peak heart rate or cardiac output $\left(\mathrm{TP}_{\mathrm{HR}}\right.$ and $\mathrm{TP}_{\mathrm{CO}}$, respectively) within each experimental treatment group. Black (atropine) and grey (sotalol). Asterisks $(*)$ denote statistically significant effects of the pharmacological treatments relative to the control at $10{ }^{\circ} \mathrm{C}$. The inset tables show statistical details from the mixed model analysis, evaluating the effects of pharmacological treatments and acute warming on the recorded parameters between $10{ }^{\circ} \mathrm{C}$ (after the pharmacological injections) and $21^{\circ} \mathrm{C}$, which was the lowest individual $\mathrm{TP}_{\mathrm{CO}}$ or $\mathrm{TP}_{\mathrm{HR}}$ for both groups (indicated by the shaded area). Dissimilar letters show significant general treatment effects among treatment groups. Statistical significance was accepted at $P \leq 0.05$. Values are mean \pm SEM

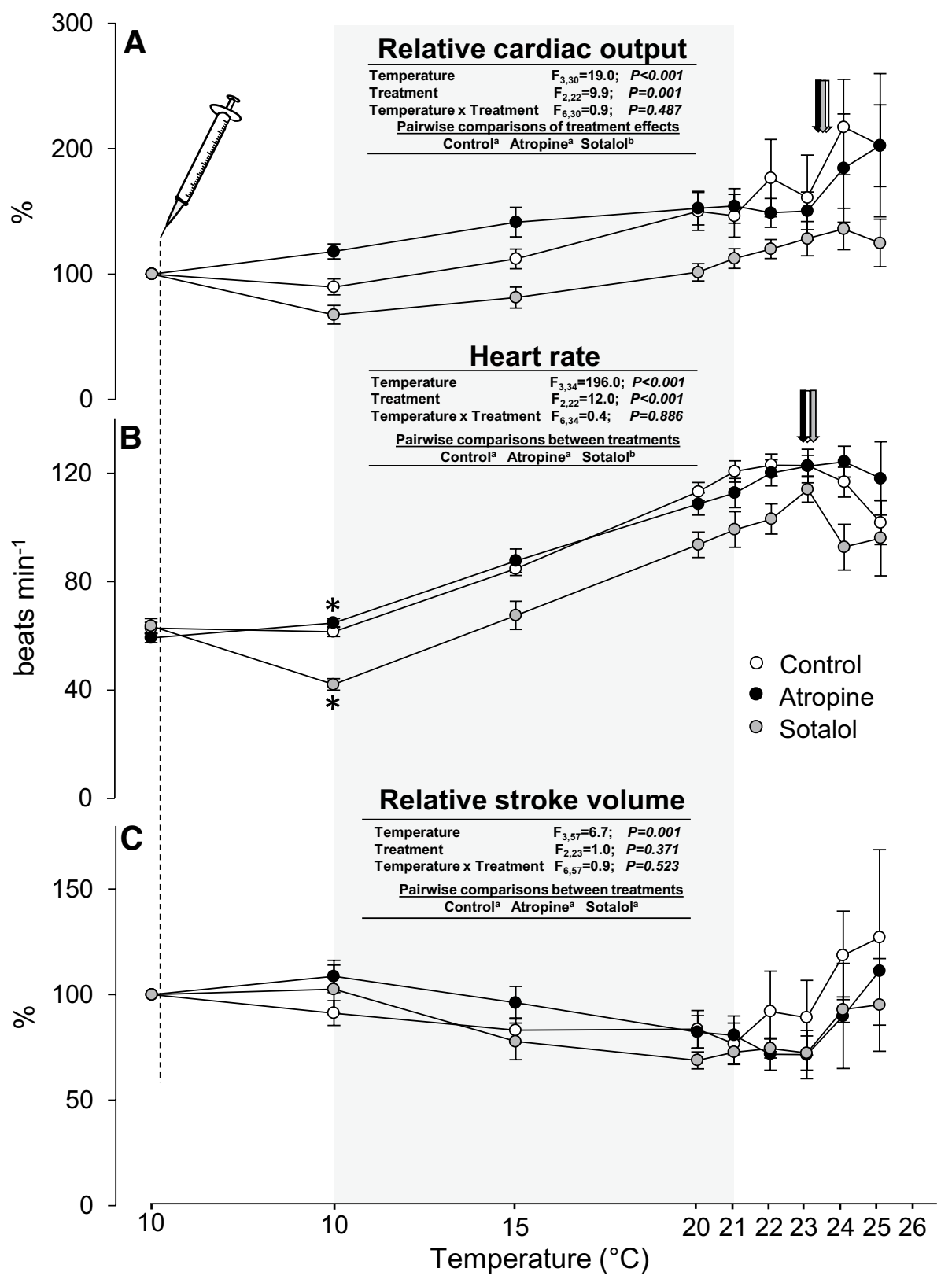

compact myocardial tissue following coronary blockade is a rapid process.

\section{Coronary perfusion improves thermal tolerance and cardiac performance during acute warming}

The difference in heart rate between trout with and without coronary perfusion was maintained during acute warming. Again, the elevated heart rate across temperatures in fish with ligated coronaries was mediated by a nearly complete release of cholinergic tone, as the heart rate response to warming was very similar in control and atropine-treated trout. The blocked coronary perfusion clearly compromised the capacity to sustain cardiac output at elevated temperatures, and the $\mathrm{TP}_{\mathrm{HR}}$ and $\mathrm{TP}_{\mathrm{CO}}$ were reached at lower temperatures than in trout with intact coronaries. The reduced $\mathrm{TP}_{\mathrm{HR}}$ with coronary ligation corroborates our previous findings in trout acclimated to the same temperature and occurred at a similar temperature $\left(\sim 23{ }^{\circ} \mathrm{C}\right.$; in Ekström et al. (2017). The earlier onset of cardiac failure in fish without coronary perfusion was associated with lowered $\mathrm{CT}_{\max }$, which highlights the potential relationship between these traits in trout. These findings strongly support our hypothesis that coronary perfusion plays an essential role for maintaining cardiac performance during warming. Indeed, compromised cardiac output likely also explains the reductions in maximum metabolic rate and aerobic scope (Ekström et al. 2018), as well as the reduced maximum swimming speed 

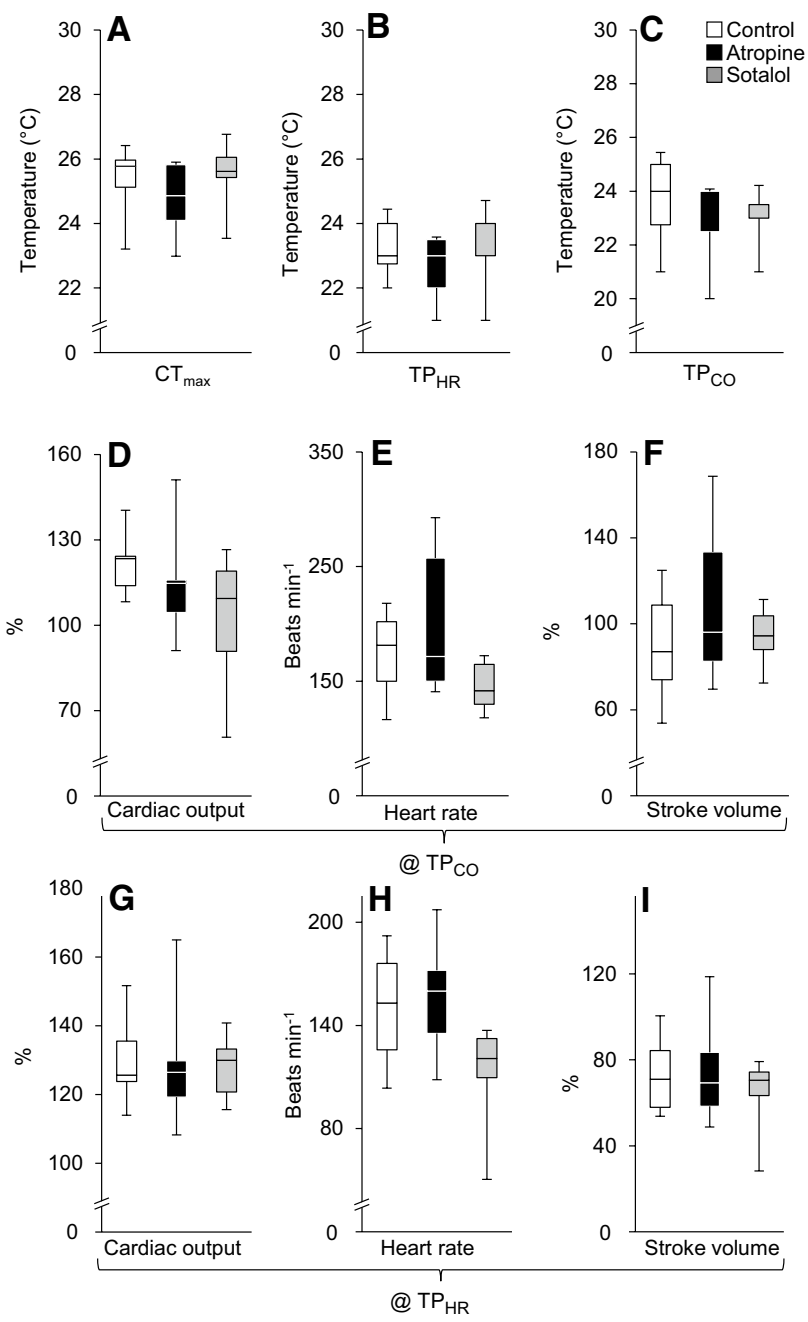

Fig. 6 Thermal limits of cardiovascular variables in coronary-ligated rainbow trout (Oncorhynchus mykiss) after autonomic blockade. a The critical thermal maximum $\left(\mathrm{CT}_{\max }\right)$ and $\mathbf{b}, \mathbf{c}$ temperatures for peak heart rate or cardiac output $\left(\mathrm{TP}_{\mathrm{HR}}\right.$ and $\mathrm{TP}_{\mathrm{CO}}$, respectively). Panels $\mathbf{d}-\mathbf{f}$ display heart rate, cardiac output and stroke volume and relative stroke volume at $\mathrm{TP}_{\mathrm{CO}}$, and panels $\mathbf{g}$-i display the same variables at $\mathrm{TP}_{\mathrm{HR}}$. Fish were injected with either $0.9 \% \mathrm{NaCl}$ (control, white bars, $n=7)$, atropine $\left(1.2 \mathrm{mg} \mathrm{kg}^{-1}\right.$, black bars, $\left.n=7\right)$ or sotalol $\left(2.7 \mathrm{mg} \mathrm{kg}^{-1}\right.$, grey bars, $\left.n=8\right)$. No significant differences were observed between treatment groups for any of the variables

(Farrell and Steffensen 1987) observed previously in salmonids with blocked coronary flow.

Although heart rate peaked at lower temperatures in trout with blocked coronaries, the maximum heart rate reached during warming was remarkably similar at $\sim 120$ to 130 beats $\mathrm{min}^{-1}$ in trout with intact and blocked coronaries. This is consistent with an upper maximum limit for heart rate in salmonids (Farrell 1991). Importantly, our findings also show that trout with ligated coronaries could not increase heart rate further, which meant that cardiac output also peaked at a lower temperature. Consequently, while the relative increase in cardiac output from baseline to $\mathrm{TP}_{\mathrm{CO}}$ in trout with intact coronary flow was corroborated our previous study (280\% increase vs. $221 \%$ increase in (Ekström et al. 2014)), blockade of coronary blood flow in the present study led to a $\sim 50 \%$ reduction in the peak cardiac output response during warming compared to sham-operated trout. Taken together, these observations strongly suggest that stroke volume is severely constrained across temperatures in trout hearts deprived of coronary perfusion. While data on absolute cardiac output across temperatures in coronary-ligated salmonids is currently unavailable, this conclusion is consistent with the study on exercising Northern squawfish by Kolok and Farrell (1994). They found that coronary ligation reduced maximum absolute stroke volume and cardiac output by $\sim 30 \%$ in large specimens, while maximum heart rate was unchanged.

The supposedly impaired stroke volume and cardiac output in trout with blocked coronary blood flow likely reflected the fact that $35-40 \%$ of the ventricle (based on the proportion of compact myocardium) was directly deprived of oxygen, such that cardiac aerobic metabolism was constrained, which should be exaggerated at higher temperatures as cardiac workload and oxygen demand increase (Ekström et al. 2016). It should be noted, however, that we cannot exclude that the impaired cardiac performance was also partially attributed to an abolished supply of endocrine factors (e.g., catecholamines) to the compact myocardial layer, which are known to increase during warming and may benefit cardiac performance (Currie et al. 2013; LeBlanc et al. 2012; Forster et al. 1998). Moreover, there are other less direct effects that can also explain the negative implications of blocked coronary flow on cardiac function. As acute warming in fish typically increases tissue oxygen extraction and reduces $P_{\mathrm{VO} 2}$ (Clark et al. 2008b; Ekström et al. 2016), an interesting possibility is that impaired cardiac output and systemic oxygen delivery in trout with ligated coronaries may have led to even greater tissue oxygen extraction and further reductions in $P_{\mathrm{VO} 2}$ to sustain tissue metabolism as temperature increased. This would translate to additionally compromised oxygen supply to the spongy myocardium, and likely exacerbate the accumulation of anaerobic by-products causing acidosis and hyperkalemia, further constraining cardiac contractility (Driedzic and Gesser 1994; Nielsen and Gesser 2001).

\section{Interactions between coronary perfusion and blood oxygen-carrying capacity in heat-stressed trout}

The reduced hematocrit and hemoglobin concentration in trout with blocked coronary blood flow suggests that lowered blood oxygen carrying capacity may at least in part explain the reduced cardiac performance and heat tolerance of this group. Indeed, the strong relationship between hematocrit and hemoglobin concentration with $\mathrm{TP}_{\mathrm{CO}}$ and $\mathrm{TP}_{\mathrm{HR}}$ found in coronary ligated trout suggests that the blood 
oxygen-carrying capacity played a crucial role for determining the upper thermal limits of cardiac performance after coronary blockade. However, no correlations with $\mathrm{CT}_{\max }$ were found, thus corroborating our previous findings in trout with unrestricted coronaries (Ekström et al. 2014).

The reason for the lower hematocrit and hemoglobin concentration in trout with ligated coronaries is not clear. What is clear is that the similar MCHC between trout with intact and ligated coronaries show that the higher hematocrit in fish with unrestricted coronaries was explained by a higher concentration of circulating erythrocytes, rather than exacerbated erythrocyte swelling (Clark et al. 2008b; Rossi et al. 2017; Zhang and Kieffer 2014). Interestingly, a similar coronary ligation procedure as used in the present study did not appear to affect hematocrit or hemoglobin concentration in rainbow trout during resting conditions (Steffensen and Farrell 1998). Thus, an intriguing possibility that needs further experimental testing is that coronary obstruction reduces the splenic release of erythrocytes that is associated with environmental stress such as warming and hypoxia in fish (see Harter and Brauner 2017; Sandblom and Axelsson 2007).

\section{Cholinergic and adrenergic blockade do not alter heat tolerance of trout with blocked coronaries}

Cholinergic tone typically increases or is maintained relatively high ( 20\%) in trout during acute warming (Ekström et al. 2014; Gilbert et al. 2019). As observed in trout with intact coronaries in the present study, this may result in a plateau in heart rate when approaching critically high temperatures (Badr et al. 2016; Ekström et al. 2016; Farrell 2007; Gilbert et al. 2019), which has been hypothesised to promote myocardial oxygenation and cardiac performance (Gilbert et al. 2019; Farrell 2007; Ekström et al. 2014). While the heart rate in trout with blocked coronaries also appeared to plateau at $\sim 120$ beats $\min ^{-1}$ between $\sim 21$ and $23{ }^{\circ} \mathrm{C}$, this response likely reflected that these fish had reached their upper functional limit for heart rate. In fact, as a similar heart rate response was observed in coronary-ligated trout treated with atropine, this again points to a general release of cholinergic tone on the heart across temperatures after coronary ligation, and that the apparent heart rate plateau at elevated temperatures was not due to active cholinergic slowing of heart rate.

Coronary blockade did not appear to affect the adrenergic tonus on the cardiac pacemaker during warming, as the difference in heart rate between coronary-ligated trout treated with sotalol and saline at $10{ }^{\circ} \mathrm{C}$ did not markedly change during the thermal challenge. Thus, consistent with previous observations in trout with unrestricted coronary flow, a relatively stable adrenergic tone elevates heart rate in trout across temperatures (Ekström et al. 2014; Gilbert et al. 2019), while an increased intrinsic pacemaker activity drives the increase in heart rate during progressive warming (see Vornanen 2016; Haverinen et al. 2016). Although adrenergic stimulation may improve maximum heart rate in thermally challenged trout, as well as in perfused trout heart preparations exposed to warming (Gilbert et al. 2019), $\beta$-adrenergic blockade had no significant effect on peak heart rate in this study. Nor did it significantly affect peak cardiac output, maximum stroke volume, or the temperatures where these variables peaked.

The present study on coronary-ligated trout is largely consistent with our previous findings in intact rainbow trout in that $\mathrm{CT}_{\max }$ and cardiac performance during warming were unaltered by autonomic blockade (Ekström et al. 2014). This contrasts with the findings of Gilbert et al. (2019), where autonomic blockade had clear and detrimental effects on these thermal performances. While these discrepancies remain unresolved, it seems unlikely that they can be explained by the minor differences in experimental methodologies between studies, which other than differences in surgical instrumentation (Doppler flow probe vs. subcutaneous electrocardiogram electrodes) were strikingly similar.

To conclude, while the evidence for a beneficial role of hormonal and autonomic neural regulation of the heart during acute heat challenge remains inconclusive, the present study provides compelling evidence that coronary perfusion benefits whole animal heat tolerance and cardiac performance during acute warming. This provides insights into how wild and farmed salmonids may be affected by sudden elevations in water temperature, as well as how cardiovascular pathologies (e.g., coronary arteriosclerosis) may affect survival and physiological performance of ectothermic animals in a more thermally extreme and variable future with climate change.

Acknowledgements Open access funding provided by University of Gothenburg. The authors thank Matthew Gilbert and Anthony Farrell for insightful discussion regarding the current research questions.

Author contributions $\mathrm{AE}$ and ES designed the experiment and $\mathrm{AE}$ conducted the experiments. AE and AG analysed the data and performed the statistical analyses. AE, ES and AG drafted and finalized the manuscript.

Funding This article was funded by Svenska Forskningsrådet Formas (Grant no. 2016-00729). This research was funded by the Swedish research council for environment, agricultural sciences and spatial planning (FORMAS) [E.S., A.G.] and the Helge Ax:son Johnson's foundation [A.E.].

\section{Compliance with ethical standards}

Conflict of interest The authors declare no conflicts of interest.

Ethical standards All experiments complied with ethical permit 1652015 issued from the regional animal ethics committee in Gothenburg, Sweden. 
Open Access This article is distributed under the terms of the Creative Commons Attribution 4.0 International License (http://creativeco mmons.org/licenses/by/4.0/), which permits unrestricted use, distribution, and reproduction in any medium, provided you give appropriate credit to the original author(s) and the source, provide a link to the Creative Commons license, and indicate if changes were made.

\section{References}

Aho E, Vornanen M (2001) Cold acclimation increases basal heart rate but decreases its thermal tolerance in rainbow trout (Oncorhynchus mykiss). J Comp Physiol [B] 171(2):173-179

Axelsson M, Farrell AP (1993) Coronary blood flow in vivo in the coho salmon (Oncorhynchus kisutch). Am J Physiol 264(5 Pt 2):R963-R971

Badr A, El-Sayed MF, Vornanen M (2016) Effects of seasonal acclimatization on temperature-dependence of cardiac excitability in the roach, Rutilus rutilus. J Exp Biol 1:4. https://doi. org/10.1242/jeb.138347

Beitinger TL, Bennett WA, McCauley RW (2000) Temperature tolerances of North American freshwater fishes exposed to dynamic changes in temperature. Environ Biol Fishes 58(3):237-275. https://doi.org/10.1023/A:1007676325825

Brijs J, Sandblom E, Dekens E, Näslund J, Ekström A, Axelsson $M$ (2016) Cardiac remodeling and increased central venous pressure underlie elevated stroke volume and cardiac output of seawater-acclimated rainbow trout. Am J Physiol Regul Integr Comp Physiol. https://doi.org/10.1152/ajpregu.00374.2016

Cech JJ Jr, Bridges DW, Rowell DM, Balzer PJ (1976) Cardiovascular responses of winter flounder, Pseudopleuronectes americanus (Walbaum), to acute temperature increase. Can J Zool 54(8): 1383-1388

Clark TD, Eliason EJ, Sandblom E, Hinch SG, Farrell AP (2008a) Calibration of a hand-held haemoglobin analyser for use on fish blood. J Fish Biol 73(10):2587-2595. https://doi.org/10.11 11/j.1095-8649.2008.02109.x

Clark TD, Sandblom E, Cox GK, Hinch SG, Farrell AP (2008b) Circulatory limits to oxygen supply during an acute temperature increase in the Chinook salmon (Oncorhynchus tshawytscha). Am J Physiol Regul Integr Comp Physiol 295(5):R1631-R1639. https://doi.org/10.1152/ajpregu.90461.2008

Currie S, Ahmady E, Watters MA, Perry SF, Gilmour KM (2013) Fish in hot water: hypoxaemia does not trigger catecholamine mobilization during heat shock in rainbow trout (Oncorhynchus mykiss). Comp Biochem Physiol A Mol Integr Physiol 165(2):281-287. https://doi.org/10.1016/j.cbpa.2013.03.014

Driedzic WR, Gesser H (1994) Energy metabolism and contractility in ectothermic vertebrate hearts: hypoxia, acidosis, and low temperature. Physiol Rev 74(1):221-258

Ekström A, Jutfelt F, Sandblom E (2014) Effects of autonomic blockade on acute thermal tolerance and cardioventilatory performance in rainbow trout, Oncorhynchus mykiss. J Therm Biol 44:47-54. https://doi.org/10.1016/j.jtherbio.2014.06.002

Ekström A, Brijs J, Clark TD, Gräns A, Jutfelt F, Sandblom E (2016) Cardiac oxygen limitation during an acute thermal challenge in the European perch: effects of chronic environmental warming and experimental hyperoxia. Am J Physiol Regul Integr Comp Physiol 311(2):R440-R449. https://doi.org/10.1152/ajpre gu. 00530.2015

Ekström A, Axelsson M, Gräns A, Brijs J, Sandblom E (2017) Influence of the coronary circulation on thermal tolerance and cardiac performance during warming in rainbow trout. Am J Physiol Regul Integr Comp Physiol 312(4):R549-R558. https ://doi.org/10.1152/ajpregu.00536.2016
Ekström A, Axelsson M, Gräns A, Brijs J, Sandblom E (2018) Importance of the coronary circulation for cardiac and metabolic performance in rainbow trout (Oncorhynchus mykiss). Biol Lett 14:7. https://doi.org/10.1098/rsbl.2018.0063

Eliason EJ, Anttila K (2017) Temperature and the cardiovascular system. In: Gamperl AK, Gillis TE, Farrell AP, Brauner CJ (eds) Fish physiology, vol 36. Academic Press, London, pp 235-297. https://doi.org/10.1016/bs.fp.2017.09.003

Ern R, Huong DTT, Phuong NT, Madsen PT, Wang T, Bayley M (2015) Some like it hot: thermal tolerance and oxygen supply capacity in two eurythermal crustaceans. Sci Rep 5:10743. https ://doi.org/10.1038/srep10743

Farrell AP (1991) From hagfish to tuna: a perspective on cardiac function in fish. Physiol Zool 64(5):1137-1164. https://doi. org/10.1086/physzool.64.5.30156237

Farrell AP (2002) Coronary arteriosclerosis in salmon: growing old or growing fast? Comp Biochem Physiol A Mol Integr Physiol 132(4):723-735

Farrell AP (2007) Tribute to P. L. Lutz: a message from the heart-why hypoxic bradycardia in fishes? J Exp Biol 210(10):1715-1725

Farrell AP, Clutterham SM (2003) On-line venous oxygen tensions in rainbow trout during graded exercise at two acclimation temperatures. J Exp Biol 206(Pt 3):487-496

Farrell AP, Smith FM (2017) Cardiac form, function and physiology. In: Gamperl AK, Gillis TE, Farrell AP, Brauner CJ (eds) Fish physiology, vol 36. Academic Press, London, pp 155-264. https ://doi.org/10.1016/bs.fp.2017.07.001

Farrell AP, Steffensen JF (1987) Coronary ligation reduces maximum sustained swimming speed in Chinook salmon, Oncorhynchus tshawytscha. Comp Biochem Physiol A 87(1):35-37

Farrell AP, MacLeod KR, Driedzic WR, Wood S (1983) Cardiac performance in the in situ perfused fish heart during extracellular acidosis: interactive effects of adrenaline. J Exp Biol 107:415-429

Farrell AP, Johansen JA, Steffensen JF, Moyes CD, West TG, Suarez RK (1990) Effects of exercise-training and coronary ablation on swimming performance, heart size and cardiac enzymes in rainbow trout (Oncorhynchus mykiss). Can J Zool 68:1174-1179

Farrell AP, Simonot DL, Seymour RS, Clark TD (2007) A novel technique for estimating the compact myocardium in fishes reveals surprising results for an athletic air-breathing fish, the Pacific tarpon. J Fish Biol 71(2):389-398. https://doi.org/10.11 11/j.1095-8649.2007.01496.x

Farrell AP, Farrell ND, Jourdan H, Cox GK (2012) A perspective on the evolution of the coronary circulation in fishes and the transition to terrestrial life. Ontogeny and phylogeny of the vertebrate heart. Springer, Berlin. https://doi.org/10.1007/978-1-4614-3387-3

Fey SB, Siepielski AM, Nussle S, Cervantes-Yoshida K, Hwan JL, Huber ER, Fey MJ, Catenazzi A, Carlson SM (2015) Recent shifts in the occurrence, cause, and magnitude of animal mass mortality events. Proc Natl Acad Sci USA 112(4):1083-1088. https://doi. org/10.1073/pnas.1414894112

Forster ME, Davison W, Axelsson M, Sundin L, Franklin CE, Gieseg S (1998) Catecholamine release in heat-stressed Antarctic fish causes proton extrusion by the red cells. J Comp Physiol [B] 168:345-352

Friedlander MJ, Kotchabhakdi N, Prosser CL (1976) Effects of cold and heat on behavior and cerebellar function in goldfish. J Comp Physiol A 112:19-45

Gamperl A, Pinder A, Grant R, Boutilier R (1994) Influence of hypoxia and adrenaline administration on coronary blood flow and cardiac performance in seawater rainbow trout (Oncorhynchus Mykiss). J Exp Biol 193(1):209-232

Gamperl AK, Axelsson M, Farrell AP (1995) Effects of swimming and environmental hypoxia on coronary blood flow in rainbow trout. Am J Physiol 269(5 Pt 2):R1258-R1266 
Gilbert MJH, Rani V, McKenzie SM, Farrell AP (2019) Autonomic cardiac regulation facilitates acute heat tolerance in rainbow trout: in situ and in vivo support. J Exp Biol 1:jeb.194365. https://doi. org/10.1242/jeb.194365

Hanson LM, Farrell AP (2007) The hypoxic threshold for maximum cardiac performance in rainbow trout Oncorhynchus mykiss (Walbaum) during simulated exercise conditions at $18{ }^{\circ} \mathrm{C}$. J Fish Biol 71(3):926-932

Hanson LM, Obradovich S, Mouniargi J, Farrell AP (2006) The role of adrenergic stimulation in maintaining maximum cardiac performance in rainbow trout (Oncorhynchus mykiss) during hypoxia, hyperkalemia and acidosis at $10{ }^{\circ} \mathrm{C}$. J Exp Biol 209(Pt 13):2442-2451

Harter TS, Brauner CJ (2017) $1-$ The $\mathrm{O}_{2}$ and $\mathrm{CO}_{2}$ transport system in teleosts and the specialized mechanisms that enhance $\mathrm{Hb}-\mathrm{O}_{2}$ unloading to tissues. In: Gamperl AK, Gillis TE, Farrell AP, Brauner CJ (eds) Fish physiology, vol 36. Academic Press, London, pp 1-106. https://doi.org/10.1016/bs.fp.2017.09.001

Haverinen J, Abramochkin DV, Kamkin A, Vornanen M (2016) The maximum heart rate in brown trout (Salmo trutta fario) is not limited by firing rate of pacemaker cells. Am J Physiol Regul Integrat Compar Physiol. https://doi.org/10.1152/ajpregu.00403.2016

Heath AG, Hughes GM (1973) Cardiovascular and respiratory changes during heat stress in rainbow trout (Salmo gairdneri). J Exp Biol 59(2):323-338

Iftikar FI, Hickey AJ (2013) Do mitochondria limit hot fish hearts? Understanding the role of mitochondrial function with heat stress in Notolabrus celidotus. PLoS One 8(5):e64120. https://doi. org/10.1371/journal.pone.0064120

Kalinin A, Gesser H (2002) Oxygen consumption and force development in turtle and trout cardiac muscle during acidosis and high extracellular potassium. J Comp Physiol [B] 172(2):145-151

Kolok AS, Farrell AP (1994) The relationship between maximum cardiac output and swimming performance in northern squawfish, Ptychocheilus oregonensis: the effect of coronary artery ligation. Can J Zool 72(9):1687-1690

LeBlanc S, Hoglund E, Gilmour KM, Currie S (2012) Hormonal modulation of the heat shock response: insights from fish with divergent cortisol stress responses. Am J Physiol Regul Integr Comp Physiol 302(1):R184-R192. https://doi.org/10.1152/ajpre gu.00196.2011

MacMillan HA (2019) Dissecting cause from consequence: a systematic approach to thermal limits. J Exp Biol 222(4):jeb191593. https://doi.org/10.1242/jeb.191593

Mendonca PC, Gamperl AK (2010) The effects of acute changes in temperature and oxygen availability on cardiac performance in winter flounder (Pseudopleuronectes americanus). Comp Biochem Physiol A Mol Integr Physiol 155(2):245-252. https://doi. org/10.1016/j.cbpa.2009.11.006

Nielsen JS, Gesser H (2001) Orthogonal polynomials of several variables, 2nd edn. Encyclopedia of mathematics and its applications, vol. 155. J Exp Biol 204(Pt 2):261-268
Overgaard J, Gesser H (2004) Force development, energy state and ATP production of cardiac muscle from turtles and trout during normoxia and severe hypoxia. J Exp Biol 207(Pt 11):1915-1924

Petersen LH, Gamperl AK (2010) In situ cardiac function in Atlantic cod (Gadus morhua): effects of acute and chronic hypoxia. J Exp Biol 213(5):820-830. https://doi.org/10.1242/jeb.033753

Roberts JC, Syme DA (2018) Effects of epinephrine exposure on contractile performance of compact and spongy myocardium from rainbow trout (Oncorhynchus mykiss) during hypoxia. Fish Physiol Biochem 44(1):49-62. https://doi.org/10.1007/s1069 5-017-0412-x

Rossi A, Bacchetta C, Cazenave J (2017) Effect of thermal stress on metabolic and oxidative stress biomarkers of Hoplosternum littorale (Teleostei, Callichthyidae). Ecol Indic 79:361-370. https:// doi.org/10.1016/j.ecolind.2017.04.042

Sandblom E, Axelsson M (2007) Venous hemodynamic responses to acute temperature increase in the rainbow trout (Oncorhynchus mykiss). Am J Physiol Regul Integr Comp Physiol 292(6):R2292-R2298

Sandblom E, Axelsson M (2011) Autonomic control of circulation in fish: a comparative view. Auton Neurosci Basic Clin 165(1):127139. https://doi.org/10.1016/j.autneu.2011.08.006

Sandblom E, Clark TD, Grans A, Ekstrom A, Brijs J, Sundstrom LF, Odelstrom A, Adill A, Aho T, Jutfelt F (2016) Physiological constraints to climate warming in fish follow principles of plastic floors and concrete ceilings. Nat Commun. https://doi. org/10.1038/ncomms11447

Steffensen JF, Farrell AP (1998) Swimming performance, venous oxygen tension and cardiac performance of coronary-ligated rainbow trout, Oncorhynchus mykiss, exposed to progressive hypoxia. Comp Biochem Physiol A Mol Integr Physiol 119(2):585-592

Stillman JH (2019) Heat waves, the new normal: summertime temperature extremes will impact animals, ecosystems, and human communities. Physiology 34(2):86-100. https://doi.org/10.1152/ physiol.00040.2018

Tota B (1983) Vascular and metabolic zonation in the ventricular myocardium of mammals and fishes. Comp Biochem Physiol A Comp Physiol 76(3):423-437

Vornanen M (2016) The temperature dependence of electrical excitability in fish hearts. J Exp Biol 219(13):1941-1952. https://doi. org/10.1242/jeb.128439

Zhang Y, Kieffer JD (2014) Critical thermal maximum $\left(\mathrm{CT}_{\max }\right)$ and hematology of shortnose sturgeons (Acipenser brevirostrum) acclimated to three temperatures. Can J Zool 92(3):215-221. https ://doi.org/10.1139/cjz-2013-0223

Publisher's Note Springer Nature remains neutral with regard to jurisdictional claims in published maps and institutional affiliations. 